\title{
C-REACTIVE PROTEIN VERSUS BLOOD CULTURE AS AN EARLY INDICATOR OF SEPSIS IN THE DIAGNOSIS OF NEONATAL SEPTICAEMIA
}

\author{
Sujit Nath Choudhury1 \\ ${ }^{1}$ Associate Professor, Department of Paediatrics, Government Medical College, Assam.
}

\section{ABSTRACT}

\section{BACKGROUND}

Aim of this study is to determine CRP as an indicator of sepsis and its statistical association with blood culture (considered as gold standard in neonatal septicaemia).

\section{MATERIALS AND METHODS}

This prospective observational study was carried out in neonatal unit of Silchar Medical College, a tertiary care teaching hospital during the period from 2014 to 2015. Both outborn as well inborn neonates admitted with neonatal septicaemia as per criteria by Vergnano et al were included in the study.

Diagnostic workup included complete Haemogram, CRP, Blood Culture and sensitivity.

Chest x-ray, Urine C\&S, CSF analysis and fungal C\&S were done wherever necessary.

\section{RESULTS}

Out of 876 cases of neonatal septicaemia cases, early onset septicaemia were 570 and rest were late onset septicaemia. Blood culture was positive in 198 (35\%) cases and 123 (40\%) cases of early onset and late onset septicaemia cases respectively. CRP test was positive in $92.52 \%$ blood culture positive cases and $50.27 \%$ blood culture negative cases.

\section{CONCLUSIONS}

Blood culture is to be done in all cases of suspected sepsis prior to starting antibiotic. A good association between blood culture positive and CRP level was found in the present study. Therefore, estimation of CRP levels and interpretation in the light of clinical picture can serve as a useful tool for the early diagnosis of neonatal sepsis.

\section{KEYWORDS}

Neonatal Sepsis, C-Reactive Protein, Blood Culture.

HOW TO CITE THIS ARTICLE: Choudhury SN.C-reactive protein versus blood culture as an early indicator of sepsis in the diagnosis of neonatal septicaemia. J. Evolution Med. Dent. Sci. 2016;5(95):7046-7048, DOI: 10.14260/Jemds/2016/1593

\begin{abstract}
BACKGROUND
Neonatal period is defined as the first 28 days of life. Before birth, the baby remains well protected in its mother's womb. After birth, the baby has to face all adverse conditions of outer world; i.e. temperature difference, large number of microorganisms, lack of nutrition supply, etc. Neonatal period is the most hazardous period of life because of various problems/diseases which a neonate faces. Neonatal septicaemia is defined as a bacterial infection documented by a positive blood culture in the first four weeks of life. Systemic bacterial infection during this period has remained a major cause of infant morbidity and mortality. According to National Neonatal Perinatal Database (NNPD), 2000 neonatal sepsis is the most common cause of deaths in the country followed by prematurity \& birth asphyxia.[1,2] To prevent serious morbidity and mortality, it is important that the diagnosis is made early and treatment started within the shortest possible time frame. Even though a positive blood culture is gold standard for
\end{abstract}

Financial or Other, Competing Interest: None.

Submission 29-08-2016, Peer Review 15-11-2016,

Acceptance 21-11-2016, Published 28-11-2016.

Corresponding Author:

Dr. Sujit Nath Choudhury,

QR-14,

Silchar Medical College

E-mail: sujitnath_2002@rediffmail.com

DOI: $10.14260 /$ jemds/2016/1593 diagnosis of neonatal sepsis, the technique is time consuming, demands a proper laboratory setup and is positive in only $40 \%$ cases. [3] Early treatment with antibiotics is possible with the help of certain indirect markers such as neutropenia $(<1800$ cells $/ \mathrm{mm} 3$ ) , leucopenia ( $<5000$ cells $/ \mathrm{mm} 3$ ), band cells, micro ESR $>15$ and CRP $>1 \mathrm{mg} / \mathrm{dL}$. All these investigations are collectively known as sepsis screen and aid in early diagnosis of neonatal sepsis in the absence of negative blood cultures. ${ }^{[4,5]}$ Thus, in presence of predisposing factors, early clinical suspicion coupled with sepsis screen will detect neonatal septicaemia early which will enable the clinician to treat the infection timely and thus reduce neonatal morbidity and mortality.[6,7]

\section{Aim of Study \\ To study CRP as an early indicator of sepsis and its statistical association with blood culture (considered as gold standard) in neonatal septicaemia.}

\section{MATERIALS AND METHODS}

This prospective observational study was carried out in the neonatal unit of tertiary care teaching hospital in northeast India during the period from 2014 to 2015 after ethical clearance from institutional ethical committee. Both out born as well as inborn neonates admitted with diagnosis of neonatal septicaemia according to criteria by Vergnano et al were included in study after informed parental consent. Septicaemia was classified into early onset septicaemia (EOS) 
and late onset septicaemia (LOS). As per standard guidelines, diagnostic workup included complete haemogram with peripheral blood smear, CRP, blood culture and sensitivity (C\&S). Chest $\mathrm{x}$-ray, Urine C\&S, cerebrospinal fluid (CSF) analysis and fungal C\&S were done wherever necessary. All specimens were collected before starting antibiotics. The CRP estimation was done with rapid slide agglutination test, using C-Reactive Protein (CRP) Reagent (Accucare) Latex test without predilution manufactured by LabCare Diagnostic (India) Pvt. Ltd. The test was performed as per the instructions given by the manufacturer. If no agglutination was observed with test, serum test was considered negative and/or CRP concentration less than $6 \mathrm{mg} / \mathrm{dL}$ which is a minimum concentration of CRP detected by this test. If marked agglutination was observed, the test was considered positive and/or CRP concentration above $6 \mathrm{mg} / \mathrm{dL}$ in the test serum. Association between CRP and blood culture positivity was assessed by McNemar's chi square test with exact McNemar significance probability with $95 \%$ conf. interval. A p value less than $0.05(<0.05)$ is considered statistically significant.

\section{RESULTS}

Over the study period, 876 neonates with neonatal septicaemia were included in the study. Amongst them, EOS was seen in 570 (65.07\%) cases and LOS in 306 (34.93\%) cases. Of the total 876 cases, $70 \%$ were delivered in hospital, $30 \%$ were delivered at home, Lower segment caesarean section (LSCS) was performed in $32 \%$ cases and instrumentation was done in $3.4 \%$ cases.

\begin{tabular}{|c|c|}
\hline CRP Titre & Number of Cases (\%) \\
\hline Test Positive (CRP > l mg/dL) & $576(65.76)$ \\
\hline Negative (CRP $<1 \mathrm{mg} / \mathrm{dL}$ ) & $300(34.24)$ \\
\hline Total & $876(100)$ \\
\hline \multicolumn{2}{|c|}{$\begin{array}{c}\text { Table 1. Shows C-reactive Protein (CRP) Levels in } \\
\text { Neonatal Septicaemia Cases }\end{array}$} \\
\hline
\end{tabular}

Out of 876 cases, CRP test was positive in 576 cases (65.76\%) and was negative in 300 cases (34.24\%).

\begin{tabular}{|c|c|c|c|}
\hline Blood Culture & EOS (\%) & LOS (\%) & Total (\%) \\
\hline Positive & $198(35)$. & $123(40)$ & $321(37)$ \\
\hline Negative & $372(65)$ & $183(60)$ & $555(63)$ \\
\hline Total & $\mathbf{5 7 0}(100)$ & $\mathbf{3 0 6}(100)$ & $\mathbf{8 7 6}(100)$ \\
\hline Table 2. Blood Culture Positivity in Early Onset and Late \\
Onset Septicaemia \\
\hline
\end{tabular}

Of the total 876 neonatal septicaemia cases, early onset septicaemia cases were 570 and late onset septicaemia cases were 306 . Of the 570 early onset neonatal septicaemia cases, blood culture was positive in 198 (35\%) cases. Similarly, out of 306 late onset neonatal septicaemia cases, blood culture was positive in 123 (40\%) cases.

Table 3 shows association of CRP with blood culture positivity in neonatal septicaemia cases. It shows that CRP test was positive in $92.52 \%$ blood culture positive cases and $50.27 \%$ blood culture negative cases and this association is statistically significant ( $\mathrm{p}$ value $=0.0000$ ).

\begin{tabular}{|c|c|c|c|}
\hline \multirow[b]{2}{*}{ Blood Culture } & \multicolumn{2}{|c|}{ CRP Test } & \multirow[b]{2}{*}{ Total } \\
\hline & $\begin{array}{l}+\mathrm{Ve} \\
(\%)\end{array}$ & -Ve (\%) & \\
\hline $\begin{array}{l}\text { Blood culture positive } \\
\text { cases }\end{array}$ & $\begin{array}{l}297 \\
(92)\end{array}$ & $24(8)$ & $321(100)$ \\
\hline $\begin{array}{l}\text { Blood culture negative } \\
\text { cases }\end{array}$ & $\begin{array}{l}279 \\
(50)\end{array}$ & $\begin{array}{l}276 \\
(50)\end{array}$ & $555(100)$ \\
\hline Total & $\begin{array}{l}576 \\
(66)\end{array}$ & $\begin{array}{l}300 \\
(34)\end{array}$ & $\begin{array}{c}876 \\
(100)\end{array}$ \\
\hline \multicolumn{4}{|c|}{$\begin{array}{l}\text { Table 3. Association of CRP with Blood Culture Positivity } \\
\text { in Neonatal Septicaemia }\end{array}$} \\
\hline
\end{tabular}

Table 4 shows association of CRP with type of neonatal septicaemia. It shows that CRP test was positive in 372 (64.58\%) cases of early onset septicaemia and 204 (35.42\%) cases of late onset septicaemia and this association is not statistically significant ( $\mathrm{p}$ value $>0.05$ ).

\begin{tabular}{|c|c|c|c|}
\hline Type of Septicaemia & CRP +Ve(\%) & CRP -Ve(\%) & Total \\
\hline EOS & $372(65)$ & $198(66)$ & 570 \\
\hline LOS & $204(35.5)$ & $102(34)$ & 306 \\
\hline Total & $\mathbf{5 7 6}(100)$ & $\mathbf{3 0 0}(100)$ & 876 \\
\hline Table 4. Association of CRP with Early Onset Septicaemia \\
and Late Onset Septicaemia \\
\hline
\end{tabular}

\section{DISCUSSION}

Neonatal septicaemia remains a challenging and important problem even with modern drug therapy. It is associated with considerable morbidity and mortality. It is difficult to diagnose the neonatal infection, because of its nonspecific clinical signs and symptoms. Microorganism detection has its value as a strong diagnostic method for neonatal septicaemia. But it is time consuming, demands a proper laboratory setup and is positive in only $40 \%$ cases so need to evaluate surrogate markers of inflammation as possible tools for early diagnosis of neonatal sepsis. Adhikari et al studied haemoglobin, total white blood cell count, differential white count, ESR, platelet count, C-reactive protein (CRP), serum immunoglobulins, plasma C3 and haptoglobin in neonatal septicaemia cases. They showed that the CRP titre (measured by latex agglutination) was the only reliable nonspecific indicator of infection. The acute phase $\mathrm{C}$-reactive protein (CRP) may increase more than 1000-fold during acute phase response. Because of its short half-life of 19 hours, CRP levels can be expected to fall quickly after efficient elimination of microbial stimulus. Thus, CRP may sufficiently reflect the individual balance between the microbe and the immune system of neonate for monitoring the effect of antibiotic treatment and for guiding the duration of antibiotic therapy. Normalisation of CRP levels has previously been proposed as a possible criterion for the discontinuation of antibiotic therapy. ${ }^{8}$ CRP estimation has established itself as one of the important test in identifying the neonatal infections. In the present study, CRP was positive in $66 \%$ cases and negative in 34\% cases (Table 1). Further, CRP test was positive in $93 \%$ blood culture positive cases and $50 \%$ blood culture negative cases. Adhikari et $\mathrm{al}^{9}$ also observed statistically significant association of CRP with blood culture positivity. The titre was elevated more often in culture positive $(16 / 19)$ than culture negative $(7 / 17)$ babies. Table 4 shows association of CRP with type of neonatal septicaemia. It shows that CRP test was positive in 375 cases of early onset 
septicaemia and 204 cases of late onset septicaemia. In the present study, blood culture positivity in neonatal septicaemia cases were 321 (37\%), whereas in 555 (63\%) of cases there was no growth (Table 2).

\section{CONCLUSIONS}

Neonatal septicaemia is one of the important causes of infant morbidity and mortality in our setup. Blood culture should be done in all cases of suspected sepsis prior to starting antibiotics. CRP has been documented to be the only nonspecific reliable indicator of infection. A good association between blood culture positivity and CRP levels was found in the present study. Hence, estimation of CRP levels and the interpretation in the light of clinical picture can serve as a useful tool for the early diagnosis of neonatal sepsis.

\section{REFERENCES}

1. National Neonatology Forum. Report of national neonatal perinatal database, New Delhi, 2000.

2. Meherban S. Perinatal infections. In: Care of newborn. 7 th edn. New Delhi: Sagar Publication 2010:223-33.

3. Buetow KC, Klein SW, Lane RB. Septicemia in premature infant: the characteristics, treatment, and prevention of septicemia in premature infants. American Journal of Diseased Child 1965;110(1):29-41.
4. Bhakoo ON. Neonatal bacterial infections at Chandigarh: a decade of experience. Indian Journal of Pediatrics 1980;47(388):419-24.

5. Waaga A, Brandtzaeg P, Hatstensen P. The complex pattern of cytokines in serum from patients with meningococcal septic shock. Association between interleukin 6, interleukin 1, and fatal outcome. J Exp Med 1989;169(1):333-8.

6. Jeevasankar M, Agarwal R, Deorari A, et al. Sepsis in newborn. Indian Journal of Pediatrics 2008;75(3):261-6.

7. Stoll Barbara J. Infections of the neonatal infant. In: Kliegman RM, Behrman RE, Jenson HB, eds. Nelson's textbook of pediatrics. $18^{\text {th }}$ edn. Philadelphia: Saunders 2007:794-811.

8. Ehl S, Gering B, Bartman P, et al. C-reactive protein is an useful marker for guiding duration of antibiotic therapy in suspected neonatal bacterial infection. Pediatr 1997;99(2):216-21.

9. Adhikari M, Coovadia HM, Coovadia YM, et al. Predictive value of C-reactive protein in neonatal septicemia. Ann Trop Paediatr 1986;6(1):37-40. 